\title{
The role of sexual vs. asexual recruitment of Artemisia wudanica in transition zone habitats between inter-dune lowlands and active dunes in Inner Mongolia, China
}

\author{
Yongcui Wang ${ }^{1}$, Busso Carlos Alberto ${ }^{2}$, Deming Jiang ${ }^{1}$, Musa Ala ${ }^{1}, X_{\text {Xehua Li }}{ }^{1}$, Quanlai Zhou ${ }^{1}$, Jixiang Lin ${ }^{3}$, \\ Guohua Ren $^{4}$, and Lian $\mathrm{Jia}^{5}$ \\ ${ }^{1}$ Institute of Applied Ecology, Chinese Academy of Sciences, Shenyang 110016, China \\ ${ }^{2}$ Departamento de Agronomía-CERZOS (CONICET: Consejo Nacional de Investigaciones Científicas y Técnicas \\ de la República Argentina), Universidad Nacional del Sur (UNSur), San Andrés 800, 8000 Bahía Blanca, Argentina \\ ${ }^{3}$ Alkali Soil Natural Environmental Science Center, Northeast Forestry University/Key Laboratory of Saline-alkali \\ Vegetation Ecology Restoration in Oil Field, Ministry of Education, Harbin 150040, China \\ ${ }^{4}$ College of Animal Science and Veterinary Medicine, Shanxi Agricultural University, Taigu 030801, China \\ ${ }^{5}$ College of Chemistry and Life Science, Anshan Normal University, 43 Pingan Street, Anshan 114005, China
}

Correspondence to: Deming Jiang (jiangdm.iae@gmail.com) and Musa Ala (alamusa@iae.ac.cn)

Received: 15 February 2016 - Published in Solid Earth Discuss.: 16 February 2016

Revised: 25 March 2016 - Accepted: 30 March 2016 - Published: 18 April 2016

\begin{abstract}
Artemisia wudanica is an endemic, perennial, pioneering psammophyte species in the sand dune ecosystems of western Horqin Sand Land in northern China. However, no studies have addressed how sexual and asexual reproduction modes of A. wudanica perform at the transitional zones between active dune inter-dune lowlands and active dunes. In early spring, quadrats were randomly set up in the study area to monitor surviving seedling and/or ramet density and frequency coming from sexual/asexual reproduction of $A$. wudanica. Iron sticks were inserted near each quadrat to determine wind erosion intensity (WE). Additionally, soil samples were collected nearby each quadrat to test for soil moisture (SM), organic matter $(\mathrm{OM})$ and $\mathrm{pH}$. Surviving seedlings of $A$. wudanica showed an inverse response in comparison with ramets to SM, OM and WE. Soil moisture showed the most positive effect, and WE the negative effect, on surviving, sexual reproduction seedlings. Contrarily, WE had the most positive effect, and SM the negative effect, on asexual reproduction ramets. This suggests that increases in SM and decreases in WE should benefit recruitment of $A$. wudanica seedlings. On the contrary, ramets coming from asexual reproduction showed a different response to environmental factors in transition zone habitats. While SM was not a key constraint for the survival of seedlings, they showed a better,
\end{abstract}

positive response to wind erosion environments. Overall, various study environmental parameters could be improved to foster A. wudanica invasion and settlement in the plant community through different reproductive modes, thereby promoting vegetation restoration and rehabilitation.

\section{Introduction}

Soil and vegetation are key components in the earth system (Raven et al., 1986; Poelking et al., 2015). In spite of this, abusive exploitation (e.g. overgrazing; intensive agriculture on fragile and coarse-textured soils) of these renewable natural resources has led to a lack of soil cover with vegetation, and subsequent soil and water losses from various types of ecosystems to a worldwide scale (Fernández and Busso, 1999; Ni et al., 2015). As a result, large surface areas in the world have been transformed into deserts because of their exploitation rather than a sustainable utilization (Dregne and Chou, 1992). Therefore, an appropriate cover of the soil with vegetation is critical to prevent degradation, and desertification, of the renewable natural resources (i.e. soil, vegetation, water resources). This has been the subject of much research, for example, in the Horqin Sand Land of China where useless 
desert, sandy areas constitute more than $27 \%$, or 2.5 million square kilometres, of the country (Jiang et al., 2014; Liu et al., 2014b).

Transition zones in sand dune ecosystems are located between sand dune systems and other ecosystems, different types of sand dunes and dune slacks. Under different environments, and their special background, different types of transition zones show variation in their structure and function (Yan et al., 2007). In recent years, research about transition zones has greatly increased as a result of the need for studies on vegetation recovery to disturbances and diversity conservation. These studies were located between sand dune systems and other ecosystems (i.e.: ocean - sand dune transition zones (Greaver and Sternberg, 2006); swamp - sand dune transition zones (Munoz-Reinoso, 2001); sand dune shrubby transition zones (Lei, 1998); and sand dune - forest transition zones; Sykes and Wilson, 1991; Oyama, 1994). However, there are few studies about inner sand dune systems (i.e. active sand dune - dune slack transition zones).

Each dune slack can be a self-containing, transition zone unit (McLachlan et al., 1996; van der Hagen et al., 2008). This is the result of the fact that while small parts of the surface area are subjected to wind erosion, transition zone surfaces are composed of wind erosion zones that have formed in recent years. Slack dunes might be isolated among themselves, and the transition zones occur here as small, naturally fragmented systems in the whole dune landscape (Bossuyt et al., 2003). The environment contrasts with that on the adjacent active dunes, and fluctuates throughout the year, maintaining available water in the winter, but being prone to drought stress in summer (Stark et al., 2003). Transition zones between active sand dunes and dune slacks in southwestern Horqin Sandy Land are characterized by a vegetation mosaic of psammophyte, limnocryptophyte-meadow and steppe species (Wang et al., 2015; Yan et al., 2007; Yan, 2007). This is where pioneering species' establishment is the initiation of community succession (Allen and Nowak, 2008). Therefore, it is essential to elucidate how pioneering species respond to transition zone habitats at different growth stages, and to establish decision-making guidelines which contribute to plant recovery after disturbance, and control of wind erosion.

Because of their ecotone nature, transition zones' ecosystems contain gradients in environmental conditions that span a wide range of variation. They frequently intensify or concentrate the flow and processing of materials; nutrient retention may also be related to their spatial pattern of variation (Traut, 2005). The spatial (e.g. area and perimeter) and soil edaphic (e.g. salinity, redox, moisture, texture) characteristics of the transition zones might reflect changes in species' richness and distribution (Cantero et al., 1998; Helzer and Jelinski, 1999). Since transition zones might be important for specific species (Morrison et al., 2001), and are sensitive to climate changes and human activities (Peters, 2002a; Puyravaud et al., 1994; Gehrig-Fasel et al., 2007), they have become a hotspot landscape unit for ecologists. However, for many transition zones, there is little understanding of the key processes that allow dominant species to persist in those zones, and how differences in these processes affect species' responses to changes in environmental conditions (Peters, 2000, 2002b).

Artemisia wudanica, a perennial psammophyte (Liu et al., 2014a), is a an endemic, major pioneering species in sand dune ecosystems of western Horqin Sand Land in northern China (Liu et al., 2007b; Yan and Liu, 2010; Wendurihu et al., 2013). It is typically found only in active dunes, where wind erosion and sand burial are severe and frequent (Liu et al., 2007a). Invasive clonal plants have two reproduction patterns, namely sexual and vegetative propagation (Qi et al., 2014). This species has unique adaptive and functional traits (Yan and Liu, 2010). It can reproduce through either seedling recruitment (sexual reproduction) or vegetative propagation (asexual reproduction; ramet production; Eriksson, 1988). There are many perennial buds on its rhizomes which may grow out to produce above-ground shoots. Artemisia wudanica can be found in Wengniute Banner and surrounding areas in western Horqin Sandy Land, and it grows in either drifting or semi-drifting dunes as a sand-fixing plant species. The distribution area of this species is narrow (Wendurihu, 2013), with a recession trend in recent years (Liu et al., 2014a).

Liu et al. (2014a) indicated that erosion has negative effects on the sexual reproduction of A. wudanica. However, whether these negative effects can extend to asexual reproduction is not known in this species. Also, the importance of knowing how various factors affect seedling frequency and abundance of $A$. wudanica was recently emphasized by Yan and Liu (2010). These authors found that (1) the number of pioneering species (e.g. A. wudanica) relative to total species number, and (2) the abundance of pioneering species relative to total abundance, decreased on active and stabilized sand dunes as the surface area increased in wetland areas. In addition, soil fine particles, soil organic $\mathrm{C}$, total $\mathrm{N}$ and $\mathrm{P}$ concentrations and the formation of biological soil crusts increase with the stabilization of sand dunes (Zhang et al., 2004; Su et al., 2005). Creation of these favourable habitats for typical dune wetland (and steppe) species also led to a high plant species' richness in inter-dune lowlands (Zhang et al., 2004; Su et al., 2005). However, Yan and Liu (2010) determined the local disappearance of the endemic, pioneering A. wudanica from inter-dune wetlands in stabilized dunes. This was because this species did not find suitable habitats in stabilized sand dunes, as a result of its adaptation to unstable substrates in active dunes. These authors reported that the increase in species' richness after dune stabilization was at the cost of the loss of endemic, pioneering species.

The importance of studying regenerative strategies on plants inhabiting active dunes in the Horqin Steppe, Inner Mongolia, north-eastern China, was highlighted by Liu et al. (2014b). They reviewed various morphological, reproductive and/or physiological adaptations in response to sand 


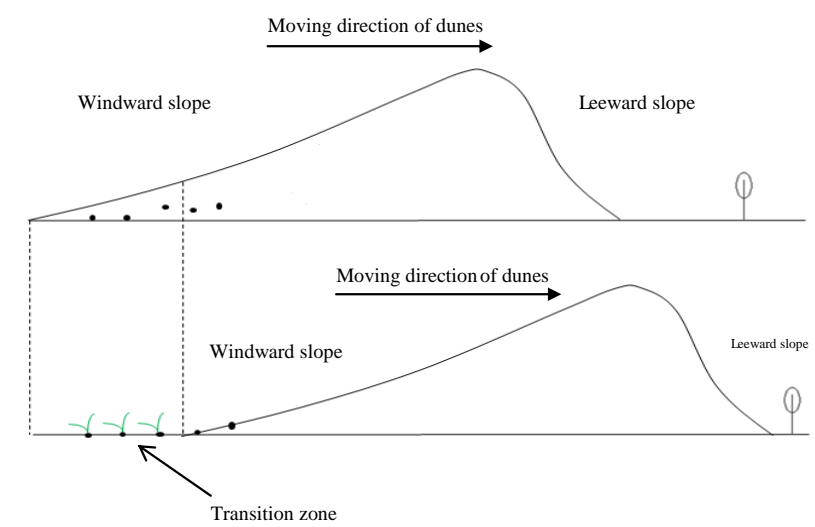

Figure 1. A sketch map showing the transition zone in inter-dune lowlands of an active sand dune system (modified from Yan et al., 2007).

burial, wind erosion or sand abrasion. These authors reported different regenerative strategies in three typical psammophytes (e.g. A. wudanica) of the Horqin Steppe in response to wind erosion. Achenes of the semi-shrub A. wudanica produce mucilage after being moistened (Liu et al., 2005) which holds sand to form a sand-binding agglomerate as a mechanism to protect psammophyte diaspora from being removed from the active sand dunes. Plants of this species fall down because of wind erosion and trap blowing sand. Thereafter, the buried, falling plants produce adventitious roots and form a cluster of emergent ramets on the active sand dunes (Liu et al., 2014b).

We hypothesized that density coming from asexual reproduction of $A$. wudanica is different from that coming from sexual reproduction in transition zone habitats of sand dune systems in north-eastern Inner Mongolia, China. We investigated the density and frequency of $A$. wudanica coming from either sexual or asexual reproduction in those habitats in the field. The relationship between sexual/asexual reproduction vs. environmental factors was also evaluated in the study species. The importance of our study lies in the need to understand the reproductive strategy of pioneering species (A. wudanica), and is especially relevant if we want to manage and restore natural ecosystems properly.

\section{Materials and methods}

\subsection{Study area}

The study was conducted in the Wulanaodu region $\left(42^{\circ} 29^{\prime}-\right.$ $43^{\circ} 06^{\prime} \mathrm{N}, 119^{\circ} 39^{\prime}-120^{\circ} 02^{\prime} \mathrm{E}$; approx. $480 \mathrm{~m}$ a.s.l.) in southwestern Horqin Sand Land, Inner Mongolia, China. The climate is semiarid, the mean annual temperature is $6.3^{\circ} \mathrm{C}$, and the frost-free period extends over 130 days. The coldest and hottest months are January and July, respectively, the maximum (July) and minimum (January) temperatures.
The mean annual precipitation is $340.5 \mathrm{~mm}, 70 \%$ of which falls between June and September. Mean annual wind velocity varies between 3.2 and $4.5 \mathrm{~m} \mathrm{~s}^{-1}$, and comes dominantly from the north-west in March-May and the south-west in June-September. The area has been intensively grazed since 1950 , and as a result, overgrazing is the major force leading to its desertification. Mobile dunes, advancing at a rate of 5-7 $\mathrm{m} \mathrm{yr}^{-1}$, are widely distributed. In this region, not only sand dune movement, but also wind erosion and sand burial, are very frequent (Wang et al., 2015). In these wind-eroded zones, vegetation is composed of only a few pioneering plant species such as Agriophyllum squarrosum (annual) and $A$. wudanica (perennial), with a coverage of less than $15 \%$.

\subsection{Experimental design}

In early April 2011, we randomly selected three dune slacks in mobile dunes. Their size was either 2.06 or 1.62 or 1.10 ha. The height of sand dunes was approximately equal around these study areas. In each of the three transition zones (see Fig. 1) with a vegetation cover of less than $5 \%$, we randomly set up nine $1 \mathrm{~m} \times 1 \mathrm{~m}$ quadrats.

\subsection{Wind erosion intensity}

Iron sticks $(2 \mathrm{~mm}$ diameter, $200 \mathrm{~cm}$ height) were inserted near each quadrat (four sticks near each quadrat) to monitor wind erosion intensity (WE; Liu et al., 2014a). In 2011, above-ground height of the sticks was measured and recorded at 5-day intervals from early April to late May, before and after seedling emergence, respectively.

\subsection{Soil physicochemical characteristics}

Ten soil samples were taken nearby each quadrat (core diameter $7.0 \mathrm{~cm}$, depth $20 \mathrm{~cm}$ ) in late May 2011. These samples were first pooled and then subdivided into 0 10 and $10-20 \mathrm{~cm}$ soil layers. Each soil sample was airdried and then sieved through a $5 \mathrm{~mm}$ screen to remove stones, roots and rhizomes. Large aggregates were gently processed by hand during the screening procedure. Sample splitting methods were applied to a total of 54 soil samples $(1$ pooled sample/quadrat $\times 2$ depths/quadrat $\times 9$ quadrats/replicate $\times 3$ replicates). These samples, repeatedly divided into halves by coning and quartering until the desired sample size was achieved, were brought to the laboratory for analyses. Soil analyses included (1) $\mathrm{pH}$, measured using a potentiometer, and (2) organic matter content, determined using the potassium dichromate heating method (Cao et al., 2011).

Also in late May 2011, four soil samples were taken close to each quadrat (core diameter $7.0 \mathrm{~cm}$, depth $30 \mathrm{~cm}$ ); vegetation and litter were removed from these samples (Karle et al., 2004). Thereafter, these samples were first subdivided into 0 $10,10-20$ and $20-30 \mathrm{~cm}$ soil layers, and immediately taken to the laboratory for soil moisture (SM) analysis. Thereafter, 
Table 1. Abbreviated codes for the species and environmental factors.

\begin{tabular}{llll}
\hline & $\begin{array}{l}\text { Abbreviated } \\
\text { code }\end{array}$ & Life form & Full name \\
\hline 1 & Ar. wu. & semi-shrub & Artemisia wudanica \\
2 & WE & - & wind erosion intensity \\
3 & SM 1 & - & soil moisture of $0-10 \mathrm{~cm}$ layer \\
4 & SM 2 & - & soil moisture of $10-20 \mathrm{~cm}$ layer \\
5 & SM 3 & - & soil moisture of $20-30 \mathrm{~cm}$ layer \\
6 & SM 4 & - & soil moisture of $0-30 \mathrm{~cm}$ layer \\
7 & OM 1 & - & organic matter of $0-10 \mathrm{~cm}$ layer \\
8 & OM 2 & - & organic matter of 10-20 cm layer \\
9 & OM 3 & - & organic matter of 0-20 cm layer \\
10 & pH 1 & - & pH of 0-10 cm layer \\
11 & pH 2 & - & pH of $10-20 \mathrm{~cm}$ layer \\
\hline
\end{tabular}

a total of 324 soil samples (4 samples/depth/quadrat $\times 9$ samples/depth/replicate $\times 3$ sampling depths/sample $\times 3$ replicates) were obtained in the field. Soil moisture content was determined by gravimetry following Brown (1995).

\subsection{Sexual and asexual reproduction}

The number of surviving either seedlings (i.e, sexual reproduction) or ramets (i.e. asexual reproduction) of $A$. wudanica was counted within each of the $27(1 \times 1 \mathrm{~m})$ quadrats in late May 2011. Remaining seed coats on surviving seedlings after their emergence helped us to distinguish their number. Whenever doubts arose for counting, soil was excavated to distinguish if individuals came from either sexual or asexual reproduction. Frequency and density were determined following Müller-Dombois and Ellenberg (1974), Liu et al. (2007a) and Wu et al. (2015). The mean number of surviving seedlings per square metre was taken as a measure of plant density (Wu et al., 2015).

$$
\begin{gathered}
\text { Density }=\text { number of individuals of a } \\
\text { species/total number of individuals } \times 100 \% \\
\text { Frequency }=\text { frequency of a species/sum frequencies } \\
\text { of all species } \times 100 \%
\end{gathered}
$$

\subsection{Data analyses}

One-way analysis of variance (ANOVA) was used to compare density and frequency between the two (i.e. sexual vs. asexual) reproduction modes of $A$. wudanica. Data to determine density were transformed to $\sqrt{ } x+0.5$ previous to analyses because neither seedlings nor ramets survived in many quadrats/replicates (i.e. there were many 0 values); untransformed values are reported in Fig. 2. Multi-way ANOVA analyses were applied using SPSS version 16.0. (SPSS for Windows, Version 16.0, Chicago, Illinois, USA) to determine correlations among $\mathrm{WE}, \mathrm{pH}$, organic matter $(\mathrm{OM})$ and $\mathrm{SM}$

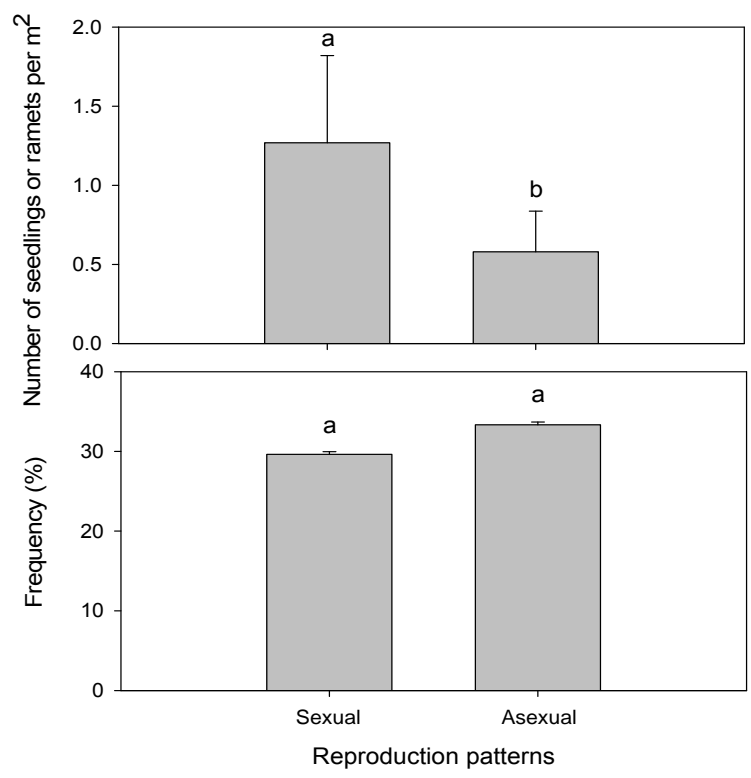

Figure 2. Density (number of surviving either seedlings (sexual reproduction) or ramets (asexual reproduction) per $\mathrm{m}^{2}$ ) and frequency (\%) coming from either sexual or asexual reproduction in the shrub A. wudanica. Histograms show the mean \pm 1 SE of $n=27$. Different letters above the histograms indicate significant differences at $p<0.05$.

vs. density of either surviving seedlings or ramets of $A$. wudanica in the transition zone habitats in active dune fields. Furthermore, redundancy analysis (RDA) using CANOCO software (2012) was used to gain insights of the relationship between the two reproductive modes of $A$. wudanica vs. WE, $\mathrm{pH}, \mathrm{OM}$ and $\mathrm{SM}$.

\section{Results}

\subsection{Environmental parameters}

From early April to late May, WE reached $4.67 \mathrm{~cm}$ (Table 2; abbreviations for the study variables are given in Table 1). In late May, SM was $13 \%$ greater at $20-30$ than $0-10 \mathrm{~cm}$ soil depth (Table 2). At this time, $\mathrm{pH}$ was $2.9 \%$ greater at 10 20 than $0-10 \mathrm{~cm}$ soil depth (Table 2). Despite WE showing a negative correlation with $\mathrm{SM}, \mathrm{OM}$ and $\mathrm{PH}$, these correlations were non-significant $(p>0.05$; Table 3$)$. SM showed positive correlations with $\mathrm{OM}$ and $\mathrm{pH} 1$ but none of these correlations were significant $(p>0.05)$. SM at $10-20 \mathrm{~cm}$ and $0-20 \mathrm{~cm}$ soil depth was positively correlated $(p<0.05)$ with $\mathrm{pH}$ at $10-20 \mathrm{~cm}$ soil depth (Table 3).

\subsection{Sexual and asexual reproduction}

We found 34 and 18 individuals coming from sexual and asexual reproduction, respectively, in all 27 plots. The mean density coming from sexual reproduction was $51 \%$ higher 
Table 2. Wind erosion intensity and soil physicochemical characteristics for the plots sampled in the transition zone. Values are mean \pm 1 standard error (SE) of $n=27$ for WE, $n=108$ for each SM depth and $n=27$ for each OM and pH depth.

\begin{tabular}{ccccccccccc}
\hline & $\begin{array}{c}\text { WE } \\
(\mathrm{cm})\end{array}$ & $\begin{array}{c}\text { SM 1 } \\
(\%)\end{array}$ & $\begin{array}{c}\text { SM 2 } \\
(\%)\end{array}$ & $\begin{array}{c}\text { SM 3 } \\
(\%)\end{array}$ & $\begin{array}{c}\text { SM 4 } \\
(\%)\end{array}$ & $\begin{array}{c}\text { OM 1 } \\
(\%)\end{array}$ & $\begin{array}{c}\text { OM 2 } \\
(\%)\end{array}$ & $\begin{array}{c}\text { OM 3 } \\
(\%)\end{array}$ & $\begin{array}{c}\text { pH 1 } \\
\text { pH 2 }\end{array}$ \\
\hline Mean & $4.67 \pm 1.00$ & $6.10 \pm 1.35$ & $6.48 \pm 1.23$ & $7.01 \pm 1.64$ & $6.53 \pm 1.39$ & $0.016 \pm 0.00$ & $0.016 \pm 0.00$ & $0.016 \pm 0.00$ & $7.32 \pm 0.01$ & $7.54 \pm 0.06$ \\
\hline
\end{tabular}

Table 3. Pearson correlation coefficients between environmental (i.e. intensity of wind erosion) and soil physicochemical variables (i.e. soil moisture and organic matter contents, and $\mathrm{pH})$ at the study site. Correlations were either non-significant or significant at the $0.01(* *)$ or $0.05\left(^{*}\right)$ level.

\begin{tabular}{lrrrrrrrrrr}
\hline $\begin{array}{l}\text { Environmental } \\
\text { parameters }\end{array}$ & $\begin{array}{r}\text { WE } \\
(\mathrm{cm})\end{array}$ & SM 1 & SM 2 & SM 3 & SM 4 & OM 1 & OM 2 & OM 3 & pH 1 & pH 2 \\
\hline WE (cm) & 1 & - & - & - & - & - & - & - & - & - \\
SM 1 (\%) & -0.170 & 1 & - & - & - & - & - & - & - & - \\
SM 2 (\%) & -0.212 & $0.969^{* *}$ & 1 & - & - & - & - & - & - & - \\
SM 3 (\%) & -0.203 & $0.962^{* *}$ & $0.965^{* *}$ & 1 & - & - & - & - & - & - \\
SM 4 (\%) & -0.197 & $0.988^{* *}$ & $0.988^{* *}$ & $0.989^{* *}$ & 1 & - & - & - & - & - \\
OM 1 (\%) & -0.202 & 0.164 & 0.083 & 0.179 & 0.147 & 1 & - & - & - & - \\
OM 2 (\%) & -0.198 & 0.269 & 0.190 & 0.304 & 0.263 & $0.888^{* *}$ & 1 & - & - & - \\
OM 3 (\%) & -0.206 & 0.229 & 0.147 & 0.256 & 0.218 & $0.964^{* *}$ & $0.978^{* *}$ & 1 & - & - \\
pH 1 & -0.045 & 0.293 & 0.286 & 0.299 & 0.297 & -0.132 & -0.124 & -0.131 & 1 & - \\
pH 2 & -0.279 & -0.026 & -0.048 & 0.015 & -0.017 & 0.334 & $0.460^{*}$ & $0.416^{*}$ & -0.063 & 1 \\
\hline
\end{tabular}

$(p<0.05)$ than that coming from asexual, vegetative reproduction (Fig. 2). Frequency was approximately $11 \%$ greater for surviving ramets coming from asexual than for surviving seedlings originated from sexual reproduction, but differences were not significant ( $p>0.05 ;$ Fig. 2$)$.

\subsection{Relationship between sexual or asexual reproduction and environmental conditions}

\subsubsection{Sexual reproduction}

The first axis of the RDA analysis explained $78.3 \%$ of the variation between the production of surviving seedlings and the environmental factors (Fig. 3). The second axis of such analysis, however, only explained $13.7 \%$ of such variation. The amount of variability explained by all canonical axes was $92 \%$. Environmental factors showed a significant effect $(p<0.05)$ on the density of surviving seedlings.

The length and angle of the arrows with respect to the small dashed, vertical lines show the degree to which the environmental factors affected seedling density. In this analysis, it was found a positive correlation between seedling density and SM $(0-10,10-20,20-30,0-30 \mathrm{~cm}), \mathrm{OM}(0-10,10$ $20,0-20 \mathrm{~cm})$ and $\mathrm{pH} 1(0-10 \mathrm{~cm})$. At the same time, a negative correlation was observed between seedling density and WE and pH $2(10-20 \mathrm{~cm})$. Additionally, SM (0-10, 10-20, $20-30,0-30 \mathrm{~cm})$ was the most relevant $(p<0.05)$ soil physical property among all study environmental factors to explain seedling density of $A$. wudanica.

\subsubsection{Asexual reproduction}

The first axis explained $73.6 \%$ of the variation between ramet density and the study environmental factors (Fig. 4). However, it was more strongly correlated with these biotic and abiotic factors than it was the first axis for sexual reproduction. The second axis explained $18.6 \%$ of the variation, and it was partially correlated with ramet density and the environmental factors. The amount of variability explained by all canonical axes was $92.2 \%$. Environmental factors had a significant effect $(p<0.01)$ on ramet density.

Wind erosion intensity and $\mathrm{pH} 1(0-10 \mathrm{~cm})$ showed positive effects on ramet density (Fig. 4). However, SM (0-10, $10-20,20-30,0-30 \mathrm{~cm}), \mathrm{OM}(0-10,10-20,0-20 \mathrm{~cm})$ and pH $2(10-20 \mathrm{~cm})$ showed negative effects on such density. Additionally, WE was the most positive $(p<0.05)$, relevant factor for ramet density.

\section{Discussion}

Vegetation recruitment occurs via sexual and asexual reproduction, depending on the species and the environmental conditions in the habitat, and this recruitment is critical for vegetation regeneration and succession (Wu et al., 2011; Qian et al., 2014). In Horqin Sand Land most plants can reproduce both sexually and vegetatively, and the balance between these two reproductive modes may vary widely between and within species. Such a balance contributes to the fact that $A$. wudanica is a successful endemic and ma- 


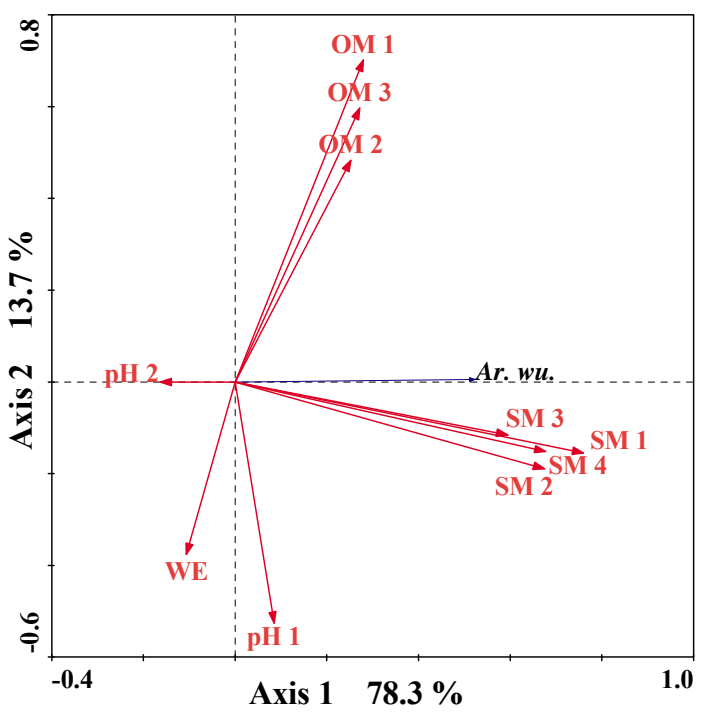

Figure 3. Redundancy analysis (RDA) of the relationship between sexual reproduction of $A$. wudanica (i.e. seedling density) and the field and environmental factors. The amount of variability explained by all the canonical axes was $92 \%(F=3.520, p=0.0100)$. Abbreviations for the study variables are given in Table 1 .

jor pioneering species in transition zone habitats of active sand dune fields in the sand dune ecosystems of western Horqin Sand Land in northern China. To date, studies were focused on seeds of $A$. wudanica (Li et al., 2012), and its frequency and abundance within dune slack areas (Yan and Liu, 2010), where sand burial compensates for $A$. wudanica seedling losses (Liu et al., 2014b). Compensation is achieved by the production of adventitious roots and emergent ramets, and modification of the biomass partitioning to above- and below-ground organs in this species on active dunes (Liu et al., 2014a). However, no studies dealt with the recruitment of A. wudanica in transition zone habitats. In these habitats, seedling and ramet densities of $A$. wudanica showed different relationships with various environmental parameters (WE, SM, OM, pH; Figs. 3 and 4). Soil moisture showed the most positive effect, and WE the negative effect, on surviving, sexual reproduction seedlings. Contrarily, WE had the most positive effect, and SM the negative effect, on asexual reproduction ramets. Therefore, our hypothesis that density coming from asexual reproduction of $A$. wudanica is different from that coming from sexual reproduction in transition zone habitats was supported.

The predominance of sexual reproduction in all 27 study plots (Fig. 2) suggests that seeds play an important role in A. wudanica preservation in transition zone habitats. Previous studies suggested, however, that $A$. wudanica population recruitment most often takes place as a result of vegetative reproduction (Li et al., 2012; Liu et al., 2014b). Similarly, Zhao et al. (2013) found that while asexual recruitment made a major contribution to the increase of total offspring num-

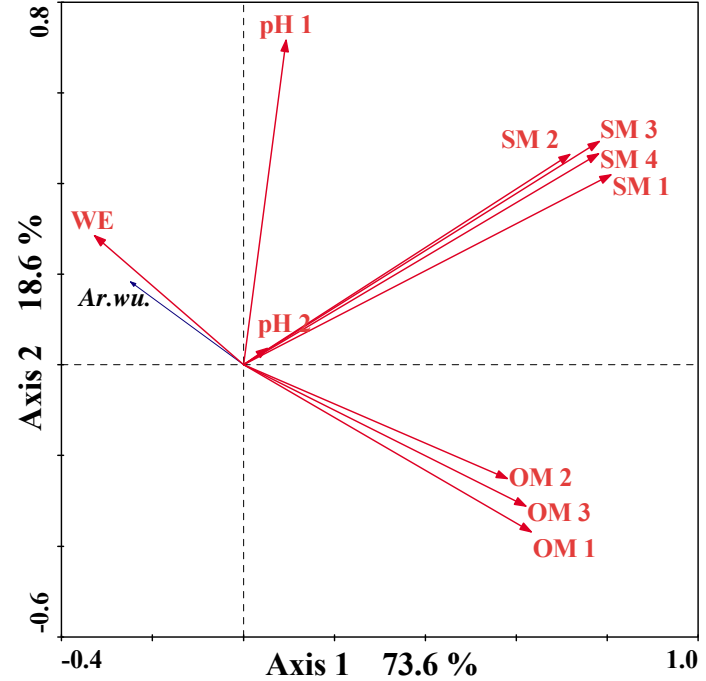

Figure 4. Redundancy analysis (RDA) of the relationship between asexual reproduction of $A$. wudanica (i.e. ramet density) and the field and environmental factors. The amount of variability explained by all the canonical axes was $92.2 \%(F=2.864, p=0.0080)$. Abbreviations for the study variables are given in Table 1 .

ber after fire, sexual recruitment contributed little to post-fire recovery in a semiarid perennial steppe of the Loess Plateau of north-western China; lack of sexual recruitment was not related to fire management but to inherent traits of the occurring plant species. Wu et al. (2013) also showed that rapid recovery after fire of an arid steppe on the Loess Plateau was mainly attributed to the removal of litter, which provided better microhabitats for the vegetative, asexual regeneration of perennial species. The higher density of sexual than asexual reproduction (Fig. 2) indicates that surviving seedlings most likely showed an aggregate spatial distribution in the soil. This is because this distribution pattern has been reported to facilitate growth of plant individuals within a patch (Holmgren et al., 1997; Schleicher et al., 2011). Ma et al. (2010) indicated that the delay in seed dispersal, and maintenance of high seed viability, after maturation until the end of the windy season and the start of the next growing season is a mechanism which allows the adaptation of the psammophyte A. wudanica to sand mobility. Our results are consistent with the redundancy analysis (RDA) in that the density of surviving seedlings showed a maximum, positive correlation with SM at all study layers, and a negative correlation with WE (Fig. 3). Xue et al. (2014) reported that even though plant recovery was limited because of the low density and high mortality of seedlings during early stages after a disturbance, long-term plant development would be of benefit to a whole population.

Generally, low levels of nutrients in coastal dune soils limit plant growth (Gilbert et al., 2008). Nutrient constraints may play a role in limiting the ability of plants to respond to sand drift activity (Gilbert et al., 2008). Wu et al. (2013) 
reported that nutrient availability was indirectly related to seedling recruitment on five Saussurea species (Asteraceae) from the Qinghai-Tibetan Plateau in China by influencing their seedling relative growth rate and root/shoot dry mass ratio. Our findings agree with those of Yan and Xu (2012) who showed that soil moisture was the most limiting factor in the process of vegetation invasion in transition zone habitats of semiarid sand dunes. In our study, recruitment from different reproduction modes showed different responses to environmental factors. It is well known that individuals coming from asexual reproduction are nourished by soil resources obtained via their mother plants (Pitelka and Ashmun, 1985; Marshall, 1990; de Kroon et al., 1996), and that these plants can absorb more water and nutrients from the soil through their flourishing roots. These studies might help explain why SM and OM depicted a negative effect on surviving ramet density in our study. The ability to get water and nutrients from the soil is rather weak on seedlings with undeveloped roots. This is why we found a positive correlation between the density of surviving seedlings and SM and OM. However, the correlation between the density of those surviving seedlings and WE was negative (Fig. 3). Water and nutrient limitation may play a significant role in limiting the ability of A. wudanica sexual reproduction to respond to wind erosion.

Soils in the $0-10$ and $10-20 \mathrm{~cm}$ layers were weakly alkaline $(\mathrm{pH}>7)$. Slightly higher $\mathrm{pH}$ content below $10 \mathrm{~cm}$ might be due to the calcareous groundwater and surface water being able to re-enter most slacks in spring, and this might have led to higher pHs in most slacks (Grootjans et al., 2002). Our results also suggested that while $\mathrm{pH} 1$ (the topsoil) showed a positive effect on density resulting from sexual and asexual reproduction, $\mathrm{pH} 2$ had a negative effect on the density of both reproduction types (Figs. 3, 4); however, the negative effect on the density of ramets was so weak that it could be considered negligible (Fig. 4). This result would indicate that the density of surviving seedlings will decrease as soil $\mathrm{pH}$ increases in the $10-20 \mathrm{~cm}$ layer, and alkaline soils are unfavourable for the successful establishment from sexual reproduction. Contrarily, alkaline soils in the $10-20 \mathrm{~cm}$ soil layer had little effect on the establishment of asexually originated individuals.

\section{Conclusions}

Artemisia wudanica showed different responses to environmental parameters between its two study reproduction modes. This partially indicates why $A$. wudanica is a major pioneering sand dune species in the sand dune ecosystems of western Horqin Sand Land in northern China. This species can invade and establish in dune slacks through different reproductive modes with changes in environmental conditions. This study revealed that we could improve the various study environmental parameters to foster $A$. wudanica in- vasion and settlement through different reproductive modes, thereby promoting vegetation restoration and rehabilitation.

Acknowledgements. We thank Yongming Luo for assistance with field work and Mark K. J. Ooi for useful advice on an earlier version of this manuscript. This research was funded by the Doctoral Scientific Research Foundation of Liaoning province (201501038) and the National Natural Science Foundation of China (31370706 and 41271115). Carlos Alberto Busso thanks (1) the sabbatical leave given by Universidad Nacional del Sur and the Consejo Nacional de Investigaciones Científicas y Técnicas de la República Argentina (CONICET), (2) the associateship awarded by the Third World Academy of Sciences (TWAS)-UNESCO, and (3) housing, facilities and financial support from the Institute of Applied Ecology, Chinese Academy of Sciences, Shenyang, China.

Edited by: A. Cerdà

\section{References}

Allen, E. A. and Nowak, R. S.: Effect of pinyon-juniper tree cover on the soil seed bank, Rangeland Ecol. Manag., 61, 63-73, doi:10.2111/07-007R2.1, 2008.

Bossuyt, B., Honnay, O., and Hermy, M.: An island biogeographical view of the successional pathway in wet dune slacks, J. Veg. Sci., 14, 781-788, doi:10.1111/j.1654-1103.2003.tb02210.x, 2003.

Brown, R. W.: The water relations of range plants: Adaptations to water deficits, in: Wildland plants: Physiological ecology and developmental morphology, edited by: Bedunahy, D. J. and Sosebee, R. E., Society for Range Management, Denver, Colorado, 291-413, 1995.

CANOCO software: Canoco5 Support Site, available at: http:// www.canoco5.com (last access: 15 January 2016), 2012.

Cantero, J. J., Cisneros, J. M., Zobel, M., and Cantero, A.: Environmental relationships of vegetation, Patterns in saltmarshes of central Argentina, Folia Geobot., 33, 133-145, doi:10.1007/Bf02913341, 1998.

Cao, C. Y., Jiang, S. Y., Zhang, Y., Zhang, F., and Han, X. S.: Spatial variability of soil nutrients and microbiological properties after the establishment of leguminous shrub Caragana microphylla Lam, plantation on sand dune in the Horqin Sandy Land of Northeast China, Ecol. Eng., 37, 1467-1475, doi:10.1016/j.ecoleng.2011.03.012, 2011.

de Kroon, H., Fransen, B., and van Rheenen, J. W. A.: High levels of inter-ramet water translocation in two rhizomatous Carex species, as quantified by deuterium labelling, Oecologia, 106, 73-84, 1996.

Dregne, H. E. and Chou, N. T.: Global desertification dimensions and costs, in: Degradation and Restoration of Arid Lands, edited by: Dregne, H. E., Texas Tech University, Lubbock, Texas, 24982, 1992.

Eriksson, O.: Ramet behaviour and population growth in the clonal herb potentilla anserina, J. Ecol., 76, 522-536, 1988.

Fernández, O. A. and Busso, C. A.: Arid and semi-arid rangelands: two thirds of Argentina, in: Case Studies of Rangeland Desertification, edited by: Arnalds, O. and Archer, S., Agricultural Research Institute Report Nro. 200, Reykjavik, Iceland, 41-60, 1999. 
Gehrig-Fasel, J., Guisan, A., and Zimmermann, N. E.: Tree line shifts in the Swiss Alps: Climate change or land abandonment?, J. Veg. Sci., 18, 571-582, doi:10.1111/j.16541103.2007.tb02571.x, 2007.

Gilbert, M., Pammenter, N., and Ripley, B.: The growth responses of coastal dune species are determined by nutrient limitation and sand burial, Oecologia, 156, 169-178, doi:10.1007/s00442-0080968-3, 2008.

Greaver, T. L. and Sternberg, L. L. D.: Linking marine resources to ecotonal shifts of water uptake by terrestrial dune vegetation, Ecology, 87, 2389-2396, dio:10.1890/00129658(2006)87[2389:Lmrtes]2.0.Co;2, 2006.

Grootjans, A. P., Geelen, H. W. T., Jansen, A. J. M., and Lammerts, E. J.: Restoration of coastal dune slacks in the Netherlands, Hydrobiologia, 478, 181-203, doi:10.1023/A:1021086832201, 2002.

Helzer, C. J. and Jelinski, D. E.: The relative importance of patch area and perimeter-area ratio to grassland breeding birds, Ecol. Appl., 9, 1448-1458, doi:10.2307/2641409, 1999.

Holmgren, M., Scheffer., M., and Huston, M. A.: The interplay of facilitation and competition in plant communities, Ecology, 78, 1966-1975, doi:10.1890/00129658(1997)078[1966:TIOFAC]2.0.CO;2, 1997.

Jiang, D., Tang, Y., and Busso, C. A.: Effects of vegetation cover on recruitment of Ulmus pumila L, in Horqin Sandy Land, Northern China., J. Arid Land, 6, 343-351, 2014.

Karle, V. S., van den Bogert, J. C. J. M., and Berendse, F.: Changes in soil and vegetation during dune slack succession, J. Veg. Sci., 15, 209-218, doi:10.1658/11009233(2004)015[0209:CISAVD]2.0.CO;2, 2004.

Lei, S. A.: Soil properties of the Kelso Sand Dunes in the Mojave Desert, Southwest Naturalist, 43, 47-52, 1998.

Li, X., Jiang, D., Musa, A., Zhou, Q., and Oshida, T.: Comparison of seed germination of four Artemisia species (Asteraceae) in northeastern Inner Mongolia, China, J. Arid Land, 4, 36-42, doi:10.3724/sp.j.1227.2012.00036, 2012.

Liu, Z., Yan, Q., Luo, Y., Wang, H., Li, R., Li, X., and Jiang, D.: Comparison of mucilage produced by achenes of 5 Artemisia species under different rainfall treatments, Acta Ecologica Sinica, 6, 1497-1501, 2005 (in Chinese).

Liu, B., Liu, Z., and Guan, D.: Seedling growth variation in response to sand burial in four Artemisia species from different habitats in the semi-arid dune field, Trees, 22, 41-47, doi:10.1007/s00468007-0167-6, 2007a.

Liu, Z. M., Li, X. L., Yan, Q. L., and Wu, J. G.: Species richness and vegetation pattern in interdune lowlands of an active dune field in inner Mongolia, China, Biol. Conserv., 140, 29-39, doi:10.1016/j.biocon.2007.07.030, 2007b.

Liu, B., Liu, Z., Lü, X., Maestre, F. T., and Wang, L.: Sand burial compensates for the negative effects of erosion on the dunebuilding shrub Artemisia wudanica, Plant Soil, 374, 263-273, doi:10.1007/s11104-013-1866-y, 2014a.

Liu, Z. M., Liu, B., and Qian, J.: Some mechanisms in reproduction of psammophyte to adapt to wind erosion on the active sand dune, Adv. Geosci., 1, 1-8, 2014b.

Ma, J., Liu, Z., Zeng, D., and Liu, B.: Aerial seed bank in Artemisia species: how it responds to sand mobility, Trees, 24, 435-441, doi:10.1007/s00468-010-0411-3, 2010.
Marshall, C.: Source-sink relations of interconnected ramets, in: Clonal Growth in Plants: Regulation and Function, edited by: van Groenendael, J. and de Kroon, H., SPB Academic Publishing, The Hague, 23-41, 1990.

McLachlan, A., Kerley, G., and Rickard, C.: Ecology and energetics of slacks in the Alexandria coastal dunefield, Landscape Urban Plan., 34, 267-276, doi:10.1016/0169-2046(95)00228-6, 1996.

Morrison, M. A. T. S. F. and Budd, R.: Detection of acoustic class boundaries in soft sediment systems using the seafloor acoustic discrimination system QTC VIEW, J. Sea Res., 46, 233-243, doi:10.1016/S1385-1101(01)00089-2, 2001.

Munoz-Reinoso, J. C.: Vegetation changes and groundwater abstraction in SW Donana, Spain, J. Hydrol., 242, 197-209, doi:10.1016/S0022-1694(00)00397-8, 2001.

Müller-Dombois, D. and Ellenberg, H.: Aims and Methods in Vegetation Ecology, New York: John Wiley and Sons, 1974.

Ni, J., Luo, D. H., Xia, J., Zhang, Z. H., and Hu, G.: Vegetation in karst terrain of southwestern China allocates more biomass to roots, Solid Earth, 6, 799-810, doi:10.5194/se-6-799-2015, 2015.

Oyama, K.: Local Differentiation among Populations of ArabisStelleri Var Japonica in a Sand Dune Habitat, Ann. Bot., 74, 103109, doi:10.1006/anbo.1994.1099, 1994.

Peters, D. P. C.: Climatic variation and simulated patterns in seedling establishment of two dominant grasses at a semi-arid-arid grassland ecotone, J. Veg. Sci., 11, 493-504, doi:10.2307/3246579, 2000.

Peters, D. P. C.: Plant species dominance at a grassland-shrubland ecotone: an individual-based gap dynamics model of herbaceous and woody specie, Ecol. Model., 152, 5-32, doi:10.1016/S03043800(01)00460-4, 2002a.

Peters, D. P. C.: Recruitment potential of two perennial grasses with different growth forms at a semiarid-arid transition zone, Am. J. Bot., 89, 1616-1623, 2002b.

Pitelka, L. F. and Ashmun, J. W.: Physiology and integration of ramets in clonal plants, in: The Population Biology and Evolution of Clonal Organisms, edited by: Jackson, J. B. G., Buss, L. W., and Cook, R. E., Yale University Press, New Haven, 399-435, 1985.

Poelking, E. L., Schaefer, C. E. R., Fernandes Filho, E. I., de Andrade, A. M., and Spielmann, A. A.: Soil-landform-plantcommunity relationships of a periglacial landscape on Potter Peninsula, maritime Antarctica, Solid Earth, 6, 583-594, doi:10.5194/se-6-583-2015, 2015.

Puyravaud, J. P., Pascal, J. P., and Dufour, C.: Ecotone Structure as an Indicator of Changing Forest Savanna Boundaries (Linganamakki Region, Southern India), J. Biogeogr., 21, 581-593, doi:10.2307/2846033, 1994.

Qi, S. S., Dai, Z. C., Miao, S. L., Zhai, D. L., Si, C. C., Huang, P., Wang, R. P., and Du, D. L.: Light limitation and litter of an invasive clonal plant, Wedelia trilobata, inhibit its seedling recruitment, Ann. Bot., 114, 425-433, doi:10.1093/aob/mcu075, 2014.

Qian, J. Q., Wang, Z. W., Liu, Z. M., and Busso, C. A.: Belowground bud bank responses to grazing intensity in the Inner-Mongolia steppe, China, Land Degrad. Dev., online first, doi:10.1002/ldr.2300, 2014.

Raven, P. H., Evert, R. F., and Eichhorn, S. E.: Biology of plants, New York, Worth Publishers, Inc. 1986.

Schleicher, J., Wieganda, K., and Ward, D.: Changes of woody plant interaction and spatial distribution between rocky and sandy soil 
areas in a semi-arid savanna, South Africa, J. Arid Environ., 75, 270-278, doi:10.1016/j.jaridenv.2010.10.003, 2011.

Stark, K. E., Lundholm, J. T., and Larson, D. W.: Relationships between seed banks and spatial heterogeneity of North American alvar vegetation, J. Veg. Sci., 14, 205-212, doi:10.1111/j.16541103.2003.tb02145.x, 2003.

Su, Y. Z., Li, Y. L., Cui, J. Y., and Zhao, W. Z.: Influences of continuous grazing and livestock exclusion on soil properties in a degraded sandy grassland, Inner Mongolia, northern China, Catena, 59, 267-278, 2005.

Sykes, M. T. and Wilson, J. B.: Vegetation of a Coastal Sand Dune System in Southern New-Zealand, J. Veg. Sci., 2, 531-538, doi:10.2307/3236035, 1991.

Traut, B. H.: The role of coastal ecotones: a case study of the salt marsh/upland transition zone in California, J. Ecol., 93, 279-290, doi:10.1111/j.1365-2745.2005.00969.x, 2005.

van der Hagen, H., Geelen, L., and de Vries, C.: Dune slack restoration in Dutch mainland coastal dunes, J. Nat. Conserv., 16, 1-11, doi:10.1016/j.jnc.2007.03.004, 2008.

Wang, Y. C., Ooi, M. K. J., Ren, G. H., Jiang, D. M., Ala, M., Miao, R., Li, X. H., Zhou, Q. L., Tang, J., and Lin, J. X.: Species shifts in above-ground vegetation and the soil seedbank in the interdune lowlands of an active dune field inInner Mongolia, China, Basic Appl. Ecol., 16, 490-499, doi:10.1016/j.baae.2015.04.010, 2015.

Wendurihu: The Research on Ecological Adaptability of Artemisia wudanica, M. S. thesis, Inner Mongolia Normal University, Inner Mongolia, China, 2013.

Wendurihu, Wang, T. J., Han, W. J., and Dai, T. T.: Allelopathy of Aqueous Extracts from Four Species Plants on Artemisia wudanica, B. Bot. Res., 33, 86-90, 2013.

Wu, G., Shang, Z., Zhu, Y., Ding, L., and Wang, D.: Speciesabundance-seed-size patterns within a plant community affected by grazing disturbance, Ecol. Appl., 25, 848-855, 2015.
Wu, G. L., Li, W., Li, X. P., and Shi, Z. H.: Grazing as a mediator for maintenance of offspring diversity: Sexual and clonal recruitment in alpine grassland communities, Flora Morphology, Distribution, Funct. Ecol. Plants, 206, 241-245, doi:10.1016/j.flora.2010.05.005, 2011.

Wu, G. L., Feng, J., Shi, Z. H., and Du, G. Z.: Plant seedling performance traits impact on successful recruitment in various microhabitats for five alpine Saussurea species, Pak. J. Bot., 45, 61-71, 2013.

Xue, Y., Zhang, W., Ma, C., Ma, L., and Zhou, J.: Relative importance of various regeneration mechanisms in different restoration stages of Quercus variabilis forest after selective logging, Forest Systems, 23, 199-208, doi:10.5424/fs/2014232-03263, 2014.

Yan, Q. L.: Roles of Sexual Reproduction in the Vegestation Restoration of Sand Dunes, PhD thesis, Chinese Academy of Sciences, Shenyang, China, 2007.

Yan, Q. L., Liu, Z. M., Ma, J. L., and Jiang, D. M.: The role of reproductive phenology, seedling emergence and establishment of perennial Salix gordejevii in active sand dune fields, Ann. Bot., 99, 19-28, 2007.

Yan, S. and Liu, Z.: Effects of dune stabilization on the plant diversity of interdune wetlands in northeastern Inner Mongolia, China, Land Degrad. Dev., 21, 40-47, doi:10.1002/ldr.966, 2010.

Yan, S. and Xu, Q.: Effect of Soil Moisture on Vegetation Invading into Transition Zone between Windward Slope of Active Dune and Interdune Lowland, J. Desert Res., 32, 1611-1616, doi:10.1890/14-0135.1, 2012.

Zhang, T. H., Zhao, H. L., Li, S. G., Li, F. R., Shirato, Y., Ohkuro, T., and Taniyama, I.: A comparison of different measures for stabilizaing moving sand dunes in the Horqin Sandy Land of Inner Mongolia, China, J. Arid Environ., 58, 203-214, 2004.

Zhao, L. P., Wu, G. L., and Shi, A. H.: Post-fire species recruitment in a semiarid perennial steppe on the Loess Plateau, Aust. J. Bot., 61, 29-35, doi:10.1071/BT12186, 2013. 